\title{
ANALYSIS OF THE PECULIARITIES OF ENCODING MESSAGES FROM VARIOUS SOURCES
}

DOI: 10.36724/2072-8735-202I-|5-9-56-62

Manuscript received 28 June 2021;

Accepted 20 July 2021

The reported study was funded by RFBR, project number 19-37-90067

Anastasia Yu. Kudryashova, Moscow Technical University of Communications and Informatics, Moscow, Russia, asykka@bk.ru

Keywords: source message coding, metric space conversion, message transmission system, isochronous signals, anisochronous signals, synchronous digital path

Information about author:

Anastasia Yu. Kudryashova, post-grad. stud., Moscow Technical University of Communications and Informatics, Moscow, Russia

Для цитирования:

Кудряшова А.Ю. Анализ особенностей кодирования сообщений от различных источников // Т-Сотт: Телекоммуникации и транспорт. 202I. Том I5. №9. С. 56-62.

For citation:

Kudryashova A.Yu. (202I). Analysis of the peculiarities of encoding messages from various sources. T-Comm, vol. I5, no.9, pp. 56-62. (in Russian)

The influence of errors on the distortion of signals transmitted and received in different spaces, in the general case, is a problem that has not yet been resolved. With the beginning of the spread of digital transmission systems, it became necessary to interface (match) various digital signals (streams) generated in accordance with the frequency of the master oscillators of individual transmission systems and terminal sources of discrete signals. At the same time, as a rule, these master oscillators operating at nominally the same frequency were not synchronized with each other. As a result, due to the real instability of the master oscillator frequencies, growing phase mismatches arose, which must be compensated. In the wellknown literature, particular cases of analysis and optimization of methods for displaying the original signal during its transformations during transmission from a source to a receiver have been investigated, and there is no general theory for studying this problem, the topic of this research is given in the article. The article examines the possibility of optimizing the choice of matching code combinations when comparing the elements of the original signal with its display when converting signals from one space to another. A method for determining the efficiency of signal conversion from one space to another is described.

(in Russian) 


\section{Introduction}

The theoretical foundations for coding source messages were laid in the fundamental works of K. Shannon [1]. The wellknown first theorem of K. Shannon for a channel where there is no interference says that for any statistics of messages coming from a source, there must be a code that, in the absence of delays on message delay, will provide the average length of the code word $\bar{n}=\mathrm{M}\left\{n_{l}\right\}$, which displays each message, arbitrarily close to the minimum possible value:

$$
n_{\min }=\frac{H(A)}{\log _{b} m}
$$

where $H(A)<\infty$ is the entropy of the source, $\mathrm{m}$ is the base of the code, and $b$ is the chosen logarithmic measure of the amount of information.

For continuous sources in formula (1), instead of the entropy value $\mathrm{H}(\mathrm{A})$, one should use the $\varepsilon$-entropy value introduced by Academician A.N. Kolmogorov [2].

Formula (1) shows the potential theoretically achievable boundary. At the same time, unfortunately, the "mechanism" for achieving this value is not disclosed. In practice, trying to achieve this minimum value, various methods are used, for example, methods of enlarging the alphabet, uneven coding, etc [3]. In this case, the formed discrete channel is, as it were, "tuned" to the corresponding statistical features of messages from the source. If the statistical description of the source changes, then the performed "tuning" can lead to worse results in ensuring efficient coding of the source.

In this sense, they say that the formed discrete channel is "opaque", since "Tuned" only to certain statistical features of messages from the source. Moreover, in a number of cases, such a channel may not be suitable at all for transmitting messages that differ in the above-mentioned characteristics from those for which the discrete channel was "tuned".

Proceeding from this, in many cases, when the statistical description of the source is not known, or the source is not stationary, uniform block coding of messages from the source is used in the form of code combinations of the same length, determined by the obvious relation [4]:

$$
n=\left\lceil\log _{2} N\right\rceil
$$

where $\mathrm{N}$ is the number of possible messages generated by the source, and the sign $\Gamma .7$ means taking an integer rounded up.

The resulting channel is called "transparent" in this case, because in this case, there is no dependence of the primary coding efficiency on the statistical features of messages from the source.

In order to achieve the minimum coding rate of the source that coincides with its entropy in binary coding, in addition to this characteristic, it is important to evaluate the complexity of the implementation and the resistance to interference [5].

The above block coding often turns out to be much simpler in practical implementation, and also makes it possible to provide greater noise immunity under the condition of interference in the communication channel, leading to errors in the discrete channel.

\section{Primary encoding of source messages}

For a detailed analysis of the processes occurring during the transformation of messages into a signal, and their subsequent transmission over the communication channel, we present a more detailed block diagram explaining and detailing the various stages of transformations. The block diagram is shown in Figure 1 $[6,7]$.

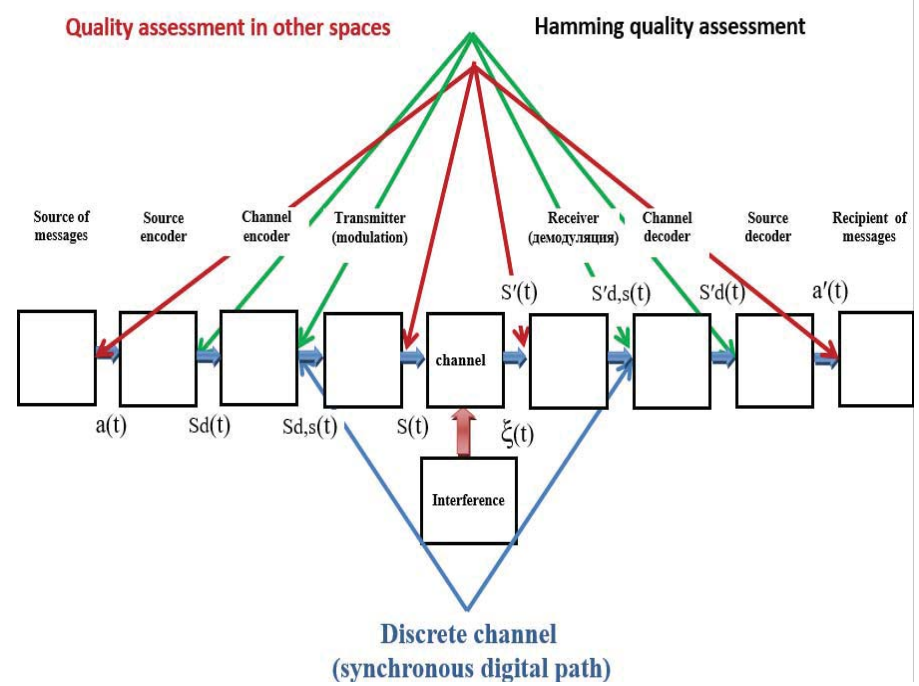

Figure 1. Block diagram of a message transmission system from a source

The message $a(t)$ from the source y is converted into a digital signal in the "Source Encoder" $s_{d}(t)$. Then this signal is converted to a digital signal $s_{d, s}(t)$, which is a modulating signal for the subsequent "Transmitter" block, to increase noise immunity in the "Channel encoder" block with the addition of a certain number of binary symbols. This block provides matching of the spectral characteristics of the signal $s(t)$ with the frequency characteristics of the channel. Moreover, this block is often called the "Modulator". At its output, a signal $s(t)$ is generated, transmitted over the communication channel. As a result of the action of interference $\xi(t)$, the signal $s^{\prime}(t)$ at the input of the "Receiver" ("Demodulator") may contain distortions, which then, after demodulation, can be transformed into errors in the signal $s_{d, s}^{\prime}(t)$ [8-10].

In the "Channel decoder" block, the errors occurring are detected and even corrected according to the selected errorcorrecting coding method. However, even after that, there may be undetected errors in the digital signal $s_{d}{ }_{d}(t)$ arriving at the Source Decoder, which then, after recovering the message, will lead to additional distortions in $a^{\prime}(t)$ [11].

Evaluation of the quality of signal transmission is carried out in the corresponding metric spaces in which these signals were displayed. Digital signals $s_{d}(t), s^{\prime}{ }_{d}(t), s_{d, s}(t)$ and $s_{d, s}{ }_{d}(t)$ are represented in Hamming space, while messages from the source 
$a(t)$ and $a^{\prime}(t)$, as well as signals $s(t)$ and $s^{\prime}(t)$, can be displayed in other spaces, often in Euclidean space [12,13].

Carrying out effective primary coding in the "Source encoder" block, and achieving, as possible, the smallest value of the average length of the codeword, each message $a(t)$ should be associated with the codeword at $s_{d}(t)$. In this case, how this correspondence will be formed does not affect the efficiency of the primary coding, since the average length of the codeword does not change [14].

However, as studies of this problem have shown, provided that there is interference in the communication channel, and as a result of this, errors occur in the digital signal, the method of matching the code combinations of the signal $s_{d}(t)$ with the messages $a(t)$ is of great importance. Depending on this, the amount of distortions introduced into the $a^{\prime}(t)$ message due to errors in the digital signal $s_{d}{ }_{d}(t)$ changes [15].

The use of correcting codes makes it possible to reduce the probability of errors arising due to interference and improve the quality characteristics of a discrete channel, estimated by the error probability, which is typical for displaying a digital signal in Hamming space [16]. However, the messages $a(t)$ and $a^{\prime}(t)$ , as well as the signals $s(t)$ and $s^{\prime}(t)$, are described in other spaces. This means that any optimization in the Hamming space with respect to digital signals does not mean optimization in general for, for example, messages $\boldsymbol{m}$ and $a^{\prime}(t)$ or signals $s(t)$ and $s^{\prime}(t)$, since the transformation of some spaces into Hamming space and back is a nonlinear operation [17-19].

The influence of errors on the distortion of signals transmitted and received in space, in the general setting, is a problem that has not been solved until now. However, there are separate results for specific types of messages and specific sizes of binary code combinations used to generate a digital signal.

Let's analyze the available solutions.

\section{Coding when pairing isochronous and anisochronous signals with a synchronous digital path}

To interface isochronous discrete signals with a synchronous digital path, the most widespread methods of stuffing are: "+ stuffing" and "- stuffing", called one-way stuffing methods, and " \pm stuffing", called the two-way stuffing method [20,21].

With these methods, the binary elements of the initial isochronous signal from the source $a_{i} \ni A$, where $A$ is the set of initial elements consisting of two values 0 and 1 , and $a_{i}$ is, respectively, the value of the current element at $i$ - the moment in time, the elements of the synchronous digital path $b_{i}$ э $B$ are assigned, where $B$ - a set of elements of a synchronous digital path, also consisting of two elements 0 and 1 .

With stuffing methods, asynchronous conjugation (coding) is based on the formation of cycles of a certain length, the beginning of which is determined by a special synchrocombination (SC) of a known type. The cycle also provides places for information symbols $b_{i}=a_{i}$, places for control commands (CU) and, if necessary, a place or place for an additional element $b_{i+1}=a_{i+1}$ (DE). Let us depict this in the diagrams for the "+ stuffing" shown in Figure 1 (a, b, c, d) and the "-staffing" shown in Figure 2 (a, b, c, d), respectively [20].

With "+ stuffing" during the cycle time $T$ from the source, taking into account the possible instability of the frequencies of the master oscillators, either $n$ elements of $\left(a_{1}, a_{2}, \ldots a_{n}\right)$, or $(n+1)$ elements of $\left(a_{1}, a_{2}, \ldots a_{n+1}\right)$. According to this, in a discrete channel in a cycle, these elements are transmitted by the values of $n$ elements of $\left(b_{1}, b_{2}, \ldots b_{n}\right)$, respectively, as shown in Figure 1 (a, b).

\begin{tabular}{|c|c|c|c|c|c|c|}
\hline$a_{1}$ & $a_{2}$ & $\ldots$ & $a_{i}$ & $\ldots$ & $a_{n-1}$ & $a_{n}$ \\
\hline \multicolumn{7}{|c|}{ 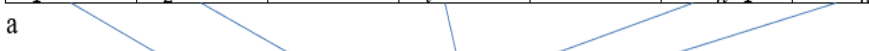 } \\
\hline $\mathrm{CK}$ & $b_{1}$ & $b_{2}$ & $\ldots$ & $b_{n}$ & КУ & ДЭ \\
\hline \multicolumn{7}{|l|}{ b } \\
\hline$a_{1}$ & $a_{2}$ & $\ldots$ & $a_{i}$ & $\ldots$ & $a_{n}$ & $a_{n+1}$ \\
\hline \multicolumn{7}{|l|}{$\mathrm{c}$} \\
\hline CK & $b_{1}$ & $b_{2}$ & $\ldots$ & $b_{n}$ & КУ & ДЭ \\
\hline
\end{tabular}

Figure 1. Timing diagrams "+ staffing"

\begin{tabular}{|c|c|c|c|c|c|c|}
\hline$a_{1}$ & $a_{2}$ & $\ldots$ & $a_{i}$ & $\ldots$ & $a_{n-1}$ & $a_{n}$ \\
\hline \multicolumn{7}{|l|}{$\mathrm{a}$} \\
\hline $\mathrm{CK}$ & $b_{1}$ & $b_{2}$ & $\ldots$ & $b_{n-1}$ & $b_{n}$ & КУ \\
\hline
\end{tabular}

\begin{tabular}{|c|c|c|c|c|c|c|}
\hline$a_{1}$ & $a_{2}$ & $\ldots$ & $a_{i}$ & $\ldots$ & $a_{n-2}$ & $a_{n-1}$ \\
\hline \multicolumn{7}{|l|}{$c$} \\
\hline CK & $b_{1}$ & $b_{2}$ & $\ldots$ & $b_{n-1}$ & $b_{n}$ & KУ \\
\hline
\end{tabular}

Figure 2. Timing diagrams of "-staffing"

Since both the $a_{i}$ elements and the $b_{i}$ elements take the value 0 or 1 , then, as already noted, information about how the DE is used is transmitted using control commands (CU). The value of the element $a_{n+1}$ is transmitted there or DE is "free" of $a_{n+1}$, and at the reception the information from this element is not read when the original signal is restored [22].

In the case of "-staffing", the values of the frequencies of the master oscillators are chosen so that during the cycle interval $T$ from the source it would come, taking into account the possible instability of the frequencies of the master oscillators, either $n$ elements of $\left(a_{1}, a_{2}, \ldots a_{n}\right)$, which is shown in Figure $1(\mathrm{a}, \mathrm{b})$, or the $(n-1)$ elements of $\left(a_{1}, a_{2}, \ldots a_{n-1}\right)$, which is shown in Figure 2 (c, d).

In this case, the DE in the cycle is not needed, and with the help of control commands of the CU, information about the element $b_{n}$ is transmitted, which in a certain sense plays the role of the DE. Accordingly, at the reception, depending on the CU, from the element $b_{n}$ either the value $a_{n}$ is read, shown in Figure $1(\mathrm{a}, \mathrm{b})$, or nothing is read, since when pairing, the value $b_{n}$ was not placed in place of the element $N$, as shown in Figure 2 (c, d). 
In practice, the method of two-way staffing has become widespread, providing for work both on the principle of "+ staffing" and "-staffing". Obviously, from the point of view of ensuring the required noise immunity, the greatest attention should be paid to the protection of control commands and SC, since their incorrect reception will lead to the insertion of an extra element, or, conversely, to the removal of a true information element.

Errors in the elements of $b_{i}$ without changes will be reflected in the form of errors among the elements of $a_{i}$. In this case, the quality of transmission and reception of elements $a_{i}$ and $b_{i}$ is estimated in the Hamming space, as a rule, through the corresponding probability distributions of correct or erroneous reception.

When isochronous signals are coupled with a synchronous digital path, a "closed" discrete channel is formed, which is tuned to the corresponding type of discrete sequence from a source of $\left(a_{1}, a_{2}, \ldots a_{n}\right)$ and a discrete sequence $\left(b_{1}, b_{2}, \ldots b_{n}\right)$ after coupling. These sequences are described in Hamming space and the main problem to be solved during coupling is smoothing the speeds of discrete signals and minimizing jitter, called jitter.

An anisochronous signal, in contrast to the considered isochronous signal, can have any element duration, but not less than a certain minimum value $\tau_{\text {min }}$, i.e. this, according to the accepted classification, it's a discrete-continuous signal, which should be converted into a discrete signal [3].

Among the methods of asynchronous conjugation of anisochronous signals, the most widespread method is the sliding index with confirmation (SIP), which has the highest conversion (coding) efficiency of a discrete-continuous signal by means of a discrete signal. Moreover, encoding with a certain quality criterion, since the original sequence of elements $\left(a_{1}, a_{2}, \ldots a_{n}\right)$ has continuous values of durations, while their display in the form of a sequence $\left(b_{1}, b_{2}, \ldots b_{n}\right)$ contains elements of a certain duration that differ from the duration of the original elements by no more than $\Delta$

In most cases, the criterion for the quality of transformation of elements of a discrete-continuous signal into a discrete one is the maximum absolute error of changing the duration of an element of the original signal $\Delta$, or the maximum value of the relative error, calculated by the formula:

$$
\delta_{\text {max }}=\frac{\Delta}{\tau_{\min }} \cdot 100 \%
$$

According to the introduced estimate of the quality of the conversion of a continuous-discrete signal into a discrete one, the minimum coding rate $\left(R_{\min }\right)$ will be determined by the epsilon entropy of the source $H\left(\varepsilon \leq \delta_{\max }\right)$, when the relative error of displaying the elements of the anisochronous signal does not exceed $\delta_{\max }$.

As already noted, the best method for pairing anisochronous signal with a discrete channel was the "sliding index with confirmation" method, in which the encoding rate was close to the theoretical limit. However, it turned out that this method is characterized by the error propagation process arising from errors in the discrete channel. In this case, the intensity of this process was also determined by the method of encoding (comparing) the elements of the original continuous-discrete (anisochronous) signal by means of discrete signal symbols transmitted over a discrete channel.

Consider examples of these processes in the diagrams shown in Figure 4 (a, b, c, d, e, f, g, h).

In the method of "sliding index with confirmation", each edge in a continuous-discrete signal (we will call a front any transition in an anisochronous signal from state 1 to state 0 and vice versa) is displayed by a code combination of a discrete signal, consisting of the so-called start symbol $A$, indicating the value of the element of the original signal, the refinement symbols $B_{1}, B_{2}, \ldots, B_{k}$ and the confirmation symbols $C$, the value of which coincides with the value of the previous start symbol and, therefore, with the value of the transmitted element of the original discrete-continuous signal.

Let us consider in more detail the transmission of elements of a continuous-discrete signal through a discrete channel using the example shown in Figure 3, when the number of refinement symbols is equal to two. The start character $A$ is used to denote the fact of the appearance of an edge in the input signal shown in diagram (a). Diagram (b) shows the clock sequence of the discrete channel symbols, the values of which are changed according to the "sliding index with acknowledgment" method. The start symbol $A$ is followed by two refinement symbols $B_{1}, B_{2}$, with the help of which the part of the clock interval in which the leading edge of the anisochronous signal element falls [21].

Since there are two damping symbols in this example, the clock interval can be divided into 4 zones, numbered 1, 2, 3, 4, assigning each corresponding code symbol value. Moreover, the assignment of the values of the qualifying symbols can be different for the case when the start symbol is 1 , or when the start symbol is 0 .

a)

b)

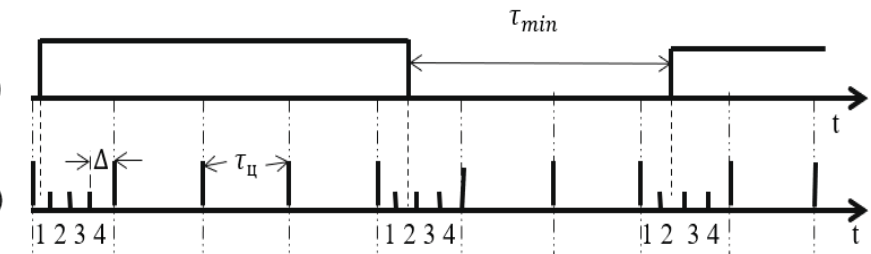

c)

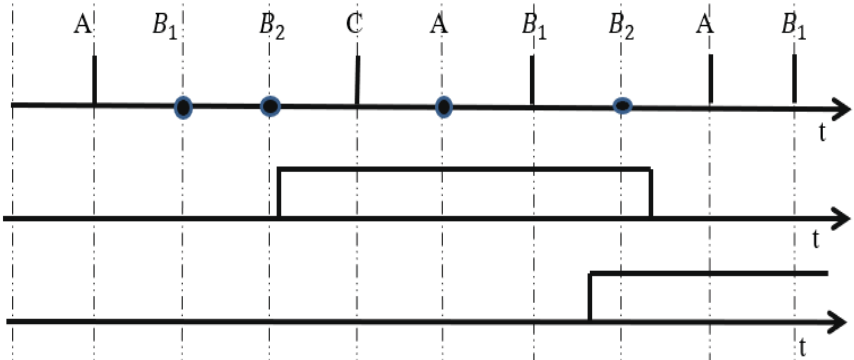

f)

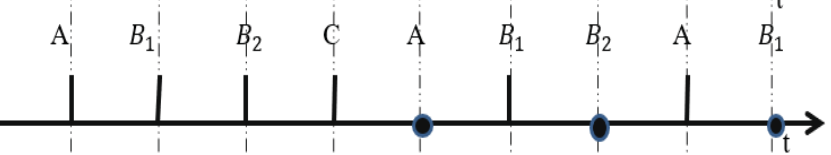

h)

)

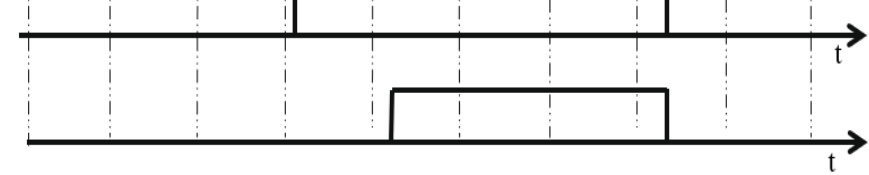

Figure 4. Method of "moving index with confirmation" 
The number of different variants of methods for setting the values of the clarifying symbols encoding the corresponding zones is obviously equal to:

$$
K=\left(2^{k}\right) !
$$

But taking into account the fact that the encoding of the qualifying symbols with the start symbol equal to 1 does not depend on the encoding method with the start symbol equal to 0 , formula (2) takes the form [16]:

$$
K=\left[\left(2^{k}\right) !\right]^{2}
$$

Applying this formula for the considered example, we find that the number of different encoding options for two refinement symbols is equal $K=576$.

For example, let's choose two options shown in Table 1.

Table 1

\section{Coding options}

\begin{tabular}{|l|c|c|l|c|c|}
\hline & \multicolumn{2}{|c|}{ Option 1 } & & \multicolumn{2}{c|}{ Option 2 } \\
\cline { 2 - 3 } \cline { 5 - 6 } & $A=1$ & $A=0$ & & $A=1$ & $A=0$ \\
\hline Zone 1 - $B_{1}, B_{2}$ & 0,0 & 0,0 & Zone $1-B_{1}, B_{2}$ & 1,1 & 0,0 \\
\hline Zone 2 - $B_{1}, B_{2}$ & 1,0 & 1,0 & Zone 2 $-B_{1}, B_{2}$ & 01 & 1,0 \\
\hline Zone 3 - $B_{1}, B_{2}$ & 0,1 & 0,1 & Zone 3 - $B_{1}, B_{2}$ & 1,0 & 0,1 \\
\hline Zone 4 - $B_{1}, B_{2}$ & 1,1 & 1,1 & Zone $4-B_{1}, B_{2}$ & 0,0 & 1,1 \\
\hline
\end{tabular}

Note that the number of refinement characters determines the precision with which the edge location between the clock interval $\tau_{u}$ characters can be encoded. In the example under consideration, the absolute error does not exceed the value

$$
\Delta=\frac{\tau_{u}}{2^{k}}=\frac{\tau_{u}}{4}
$$

And each edge of the element of the original signal, thus, is represented by three symbols of the codeword transmitted over the discrete channel.

If a front does not appear in the original signal after the code combination $A, B_{1}, B_{2}$, then a confirmation symbol $C$ is formed, which coincides in sign with the previous symbol $A$. Further, when a front appears, the combination $A, B_{1}, B_{2}$ will be formed again. If there is no front, then the formation of confirmation symbols $C$ continues.

Diagrams (c) and (f) respectively show the encoded sequences for Option 1 and Option 2 from Table 1. Diagrams (d) and (g) show the reconstructed original signals transmitted by the "sliding index with confirmation" method using different variants of coding zones with refinement symbols. Comparison shows their complete coincidence [22].

However, if an error occurs due to the effect of interference, then its consequences can be completely different.

Let us demonstrate this with an example where, due to noise, an error occurs in the first start character $A$.
For variant 1 , the code sequence $A, B_{1}, B_{2}, C, A, B_{1}, B_{2}, A, B_{1}, \ldots$ will be perceived at the reception as $C, C, C, A, B_{1}, B_{2}, A, B_{1}, B_{2}, \ldots$. Comparing these sequences, one can note the incipient process of error multiplication, when, due to one error in a discrete channel, several elements of the original signal will be incorrectly restored. An example of this is the comparison of diagrams (d) and (e).

For option 2, the same code sequence $A, B_{1}, B_{2}, C, A, B_{1}, B_{2}, A, B_{1}, \ldots$ will be perceived at the reception as $C, A, B_{1}, B_{2}, A, B_{1}, B_{2}, A, B_{1}$. This will distort one element of the original signal, but there will be no multiplication of errors. This is evidenced by the comparison of diagrams (g) and (h).

In $[20,21]$, studies of the noise immunity of the "sliding index with confirmation" method were carried out for all possible methods of encoding the clarifying symbols with $k=1$ and $k=2$, which corresponded to the cases of practical application of this method.

\section{Conclusion}

Studies have shown that a rational choice can increase the noise immunity by 2-3 times, depending on the acting noise, the $\frac{\tau_{u}}{\tau_{\min }}$ ratios and the coding methods of the clarifying symbols. In this case, as noted, the conversion efficiency of a continuousdiscrete (anisochronous) signal into a discrete signal does not change.

Optimization of the method of displaying the original signal in the presence of interference allows you to obtain a noticeable gain in noise immunity. At the same time, the coding rate remains unchanged, which is an important and significant factor, since the achieved positive effect can be obtained without any additional costs that reduce the channel capacity.

\section{Acknowledgment}

The reported study was funded by RFBR, project number 19-37-90067.

\section{References}

1. C.E. Shannon, "A Mathematical Theory of Communication", Bell System Technical Journal. 1948. Vol. 27, pp. 379-423, 623-656.

2. A.N. Kolmogorov, Basic concepts of probability theory. Moscow: Nauka, 1974.

3. A.S. Adzhemov, V.G. Sannikov, General communication theory. Textbook for universities. Moscow: Hot Line - Telecom. 2017. $624 \mathrm{p}$.

4. A.S. Adzhemov and A.Y. Kudryashova, "Features rate estimation options binary codewords with the digitalization of the signal," 2018 Systems of Signal Synchronization, Generating and Processing in Telecommunications (SYNCHROINFO), 2018, pp. 1-5, doi: 10.1109/SYNCHROINFO.2018.8456929.

5. A. S. Adzhemov and S. A. Adzhemov, "On Some Features of Binary Code Combinations," 2019 Systems of Signals Generating and 
Processing in the Field of on Board Communications, 2019, pp. 1-7, doi: 10.1109/SOSG.2019.8706817.

6. A.S. Adzhemov, "Code Distance Table and its Application," 2018 Wave Electronics and its Application in Information and Telecommunication Systems (WECONF), 2018, pp. 1-5, doi: 10.1109/WECONF.2018.8604435.

7. A.Y. Kudryashova and A. S. Adzhemov, "Building an Algorithm for Estimating the Effective Coding of a Source when Converting Signals in Various Metric Spaces," 2018 Wave Electronics and its Application in Information and Telecommunication Systems (WECONF), 2018, pp. 1-4, doi: 10.1109/WECONF.2018.8604380.

8. A.S. Adzhemov and A.Y. Kudryashova, "About Interferable Binary Code Constructions," 2020 Systems of Signal Synchronization, Generating and Processing in Telecommunications (SYNCHROINFO), 2020, pp. 1-4, doi: 10.1109/SYNCHROINFO49631.2020.9166042.

9. A. S. Adzhemov and A. Y. Kudryashova, "Model of Effective Color Image Coding Taking into Account the Peculiarities of Colorimetry System," 2019 Systems of Signal Synchronization, Generating and Processing in Telecommunications (SYNCHROINFO), 2019, pp. 1-5, doi: 10.1109/SYNCHROINFO.2019.8814193.

10. A.Y. Kudryashova, A.S. Adzhemov and I.V. Vlasuyk, "Application of Weber-Fechner Law in Image Transmission in the Field of Onboard Communications," 2019 Systems of Signals Generating and Processing in the Field of on Board Communications, 2019, pp. 1-6, doi: 10.1109/SOSG.2019.8706774.

11. A.S. Adzhemov, A. Yu. Kudryashova, "Software implementation for evaluating the efficiency of the source coding algorithm when transforming metric spaces", Proceedings of NIIR. Moscow: NIIR. 2020. No. 4. P. 17-23.

12. A.Yu. Kudryashova, "A method of efficient coding of color images under the condition of permissible and forbidden values of color gamut”. T-Comm. 2019.Vol.13.No. 6, pp. 65-70.

13. A.S. Adzhemov and A.Y. Kudryashova, "Evaluation Program of an Efficient Source Coding Algorithm Under the Condition of Converting Metric Spaces," 2019 Wave Electronics and its Application in Information and Telecommunication Systems (WECONF), 2019, pp. 1-5, doi: 10.1109/WECONF.2019.8840609.
14. A.Yu. Kudryashova, "Peculiarities of coding estimation in various configurations of the source space", DSPA: problems of digital signal processing, 2018. V. 8. No. 3. P. 228-232.

15. A.S. Adzhemov and A. Y. Kudryashova, "About features of evaluation of the quality of generation and signal processing at stage transformations in wiring and optical communication systems," 2018 Systems of Signals Generating and Processing in the Field of on Board Communications, 2018, pp. 1-4, doi: 10.1109/SOSG.2018.8350565.

16. A.S. Adzhemov and A. Y. Kudryashova, "Reducing Distortion when Applying the Rational Choice of the Digital Conversion Method," 2020 Systems of Signals Generating and Processing in the Field of on Board Communications, 2020, 1-6, d 10.1109/IEEECONF48371.2020.9078573.

17. A.S. Adzhemov, A.Y. Kudryashova, "Features of assessing the quality of signal transmission in various metric spaces". Fundamental problems of radio-electronic instrument-making. 2017. Vol. 17. No. 4. pp. 886-888.

18. A.S. Adzhemov., I.S. Sineva, "Efficiency of genetic-like coding algorithm for metric space sources”. 2-nd IEEE International conference on circuit and systems for communication, Russia, Moscow, 06. 2004. 4 p.

19. A.S. Adzhemov and A.Y. Kudryashova, "Features of Converting Signals to Binary and Minimizing Distortion," 2021 Systems of Signals Generating and Processing in the Field of on Board Communications, 2021, pp. 1-5, doi: 10.1109/IEEECONF51389.2021.9416118.

20. A.S. Adzhemov, "Reproduction of errors when transmitting a discrete message by the sliding index method with confirmation", Electrosvyaz, 1976. No. 2, pp. 9-18.

21. A.S. Adzhemov, "The choice of the way of specifying the clarifying symbols in the sliding index method with confirmation", Electrosvyaz, 1978. No. 10, pp. 15-18.

22. A.S. Adzhemov, "Limiting values of the efficiency of asynchronous coupling of a discrete signal with a synchronous digital path", Electrosvyaz, 1985. No. 3, pp. 21-28. 


\section{АНАЛИЗ ОСОБЕННОСТЕЙ КОДИРОВАНИЯ СООБЩЕНИЙ ОТ РАЗЛИЧНЫХ ИСТОЧНИКОВ}

Кудряшова Анастасия Юрьевна, Московский технический университет связи и информатики, Москва, Россия, asykka@bk.ru

\section{Аннотация}

Влияние ошибок на искажение сигналов, передаваемых и принимаемых в разных пространствах, в общем случае является проблемой, которая еще не решена. С началом распространения цифровых систем передачи возникла необходимость сопряжения (согласования) различных цифровых сигналов (потоков), порождаемых в соответствии с частотой задающих генераторов отдельных систем передачи и оконечных источников дискретных сигналов. При этом, как правило, эти задающие генераторы, работающие, в том числе, с номинально равной частотой, не были синхронизированы между собой. В результате этого в силу реально имеющейся нестабильности частот задающих генераторов, возникали нарастающие фазовые расхождения, которые надо было компенсировать. В известной литературе исследованы частные случаи анализа и оптимизации методов отображения исходного сигнала при его преобразованиях в процессе передачи от источника к получателю и нет общей теории исследования данной проблемы, тематика данного исследование приводится в статье. В статье исследуется возможность оптимизации выбора совпадающих кодовых комбинаций при сравнении элементов исходного сигнала с его отображением при преобразовании сигналов из одного пространства в другое. Описан метод определения эффективности преобразования сигналов из одного пространства в другое.

Ключевые слова: кодирование исходного сообщения, преобразование метрического пространства, система передачи сообщений, изохронные сигналы, асинхронные сигналы, синхронный цифровой тракт.

\section{Литература}

I. Shannon C.E. A Mathematical Theory of Communication. Bell System Technical Journal. 1948. Vol. 27. pp. 379-423, 623-656.

2. Колмогоров А.Н. Основные понятия теории вероятностей. М.: Наука, 1974.

3. Аджемов А.С., Санников В. Общая теория коммуникации. Учебник для вузов. М.: Горячая линия-Телеком. 2017.624 с.

4. Adzhemov A.S., Kudryashova A.Y. Features rate estimation options binary codewords with the digitalization of the signal // 2018 Systems of Signal Synchronization, Generating and Processing in Telecommunications (SYNCHROINFO), 2018, PP. I-5, doi: 10.1 109/SYNCHROINFO.2018.8456929.

5. Adzhemov A.S., Adzhemov S.A. On Some Features of Binary Code Combinations // 2019 Systems of Signals Generating and Processing in the Field of on Board Communications, 2019, Pp. I-7, doi: 10.1109/SOSG.2019.8706817.

6. Adzhemov A.S. Code Distance Table and its Application // 2018 Wave Electronics and its Application in Information and Telecommunication Systems (WECONF), 2018, pp. I-5, doi: 10.1 109/WECONF.2018.8604435.

7. Kudryashova A.Y., Adzhemov A.S. Building an Algorithm for Estimating the Effective Coding of a Source when Converting Signals in Various Metric Spaces // 2018 Wave Electronics and its Application in Information and Telecommunication Systems (WECONF), 2018, PP. I-4, doi: 10.1109/WECONF.2018.8604380.

8. Adzhemov A.S., Kudryashova A.Y. About Interferable Binary Code Constructions // 2020 Systems of Signal Synchronization, Generating and Processing in Telecommunications (SYNCHROINFO), 2020, pp. I-4, doi: I0.II 09/SYNCHROINFO4963I.2020.9166042.

9. Adzhemov A.S., Kudryashova A.Y. Model of Effective Color Image Coding Taking into Account the Peculiarities of Colorimetry System // 2019 Systems of Signal Synchronization, Generating and Processing in Telecommunications (SYNCHROINFO), 20I9, PP. I-5, doi: 10.1I09/SYNCHROINFO.2019.8814193.

10. Kudryashova A.Y., Adzhemov A.S., Vlasuyk I.V. Application of Weber-Fechner Law in Image Transmission in the Field of Onboard Communications /I 2019 Systems of Signals Generating and Processing in the Field of on Board Communications, 2019, pp. I-6, doi: 10.1 I09/SOSG.2019.8706774.

ІІ. Аджемов А.С., Кудряшова А.Ю. Программная реализация для оценки эффективности алгоритма кодирования исходного кода при преобразовании метрических пространств", Труды НИИР. М .: НИИР. 2020. № 4. С. 17-23.

12. Kudryashova A.Yu. A method of efficient coding of color images under the condition of permissible and forbidden values of color gamut // T-Comm:. 2019.Vol.13.No. 6.pp.65-70.

13. Adzhemov A.S., Kudryashova A.Y. Evaluation Program of an Efficient Source Coding Algorithm Under the Condition of Converting Metric Spaces // 2019 Wave Electronics and its Application in Information and Telecommunication Systems (WECONF), 20I9, PP. I-5, doi: 10.1 109/WECONF.2019.8840609.

14. Kudryashova A.Yu. Peculiarities of coding estimation in various configurations of the source space // DSPA: problems of digital signal processing, 2018. V. 8 . No. 3 p. $228-232$.

15. Adzhemov A.S., Kudryashova A.Y. About features of evaluation of the quality of generation and signal processing at stage transformations in wiring and optical communication systems // 2018 Systems of Signals Generating and Processing in the Field of on Board Communications, 2018, Pp. 1-4, doi: 10.1109/SOSG.2018.8350565.

16. Adzhemov A.S., Kudryashova A.Y. Reducing Distortion when Applying the Rational Choice of the Digital Conversion Method // 2020 Systems of Signals Generating and Processing in the Field of on Board Communications, 2020, pp. I-6, doi: 10.1 I09/IEEECONF4837I.2020.9078573.

17. Adzhemov A.S., Kudryashova A.Y. Features of assessing the quality of signal transmission in various metric spaces // Fundamental problems of radioelectronic instrument-making. 2017. V. 17. No. 4. pp. 886-888.

18. Аджемов А.С., Синева И.С. Эффективность алгоритма генетического кодирования для метрических пространственных источников // 2-я Международная конференция IEEE по схемам и системам связи, Россия, Москва, 06.2004.

19. Adzhemov A.S., Kudryashova A.Y. Features of Converting Signals to Binary and Minimizing Distortion // 202I Systems of Signals Generating and Processing in the Field of on Board Communications, 202I, Pp. I-5, doi: I0.II09/IEEECONF5 I389.202I.94I6II8.

20. Аджемов А.С. Воспроизведение ошибок при передаче дискретного сообщения методом скользящего индекса с подтверждением // Электросвязь, 1976. № 2. С. 9-18.

2І. Аджемов А.С. Выбор способа задания поясняющих символов в методе скользящего индекса с подтверждением // Электросвязь, І978. № 10 . C. $15-18$.

22. Аджемов А.С. Предельные значения эффективности асинхронной связи дискретного сигнала с синхронным цифровым трактом // Электросвязь, 1985. № 3. C. 21-28. 